\title{
Papiller tiroid karsinomu ve mikrokarsinomu olan hastalarda klinik, laboratuvar ve tümör özelliklerinin karşılaştırılması ve risk faktörlerinin değerlendirilmesi
}

\section{Comparison of clinical, laboratory and tumor characteristics and evaluation of risk factors in patients with papillary thyroid carcinoma and microcarcinoma}

\author{
Narin Nasıroğlu İmga1* , Hakan Ataş², Dilek Berker ${ }^{1}$ Gül Dağlar ${ }^{2}$
}

'Sağlık Bilimleri Üniversitesi, Ankara Numune Eğitim ve Araştırma Hastanesi Endokrinoloji ve Metabolizma Hastalıkları Kliniği, Ankara, Türkiye ${ }^{2}$ Sağlık Bilimleri Üniversitesi, Ankara Numune Eğitim ve Araştırma Hastanesi Meme Endokrin Cerrahisi Kliniği, Ankara, Türkiye

\section{öz}

Amaç: Papiller tiroid kanserleri karsinomu (PTK) en sık görülen kanserlerden biri olup prognozu iyi seyretmekle beraber ömür boyu takip gerektirir. Tümörün en büyük çapı $\leq 10 \mathrm{~mm}$ ise papiller mikrokarsinom (PTMK) olarak adlandırılır. İleri yaş, tümör boyutu, odak sayısı fazlalığı, ekstratiroidal ekstansiyon, patolojik lenf nodu (LN) ve uzak metastaz varlığı PTK prognozunu olumsuz etkiler. Amacımız PTK ve PTMK hastalarında klinik, laboratuvar ve tümör özelliklerini karşılaştırmaktır.

Gereç ve Yöntem: Ankara Numune Eğitim ve Araştırma Hastanesinde Nisan 2014 ve Ekim 2017 tarihleri arasında total tiroidektomi yapılan 302 PTK hastası retrospektif olarak incelendi. Postoperatif tümör boyutu, tümör odak sayısı, lokalizasyonu ve ekstratiroidal ekstansiyon durumu kaydedildi.

Bulgular: Hastalar \%80,8 kadın, \%19,2 erkekti. Yaş ortalaması 46,48土12,3 iken vücut kitle indeksi (VKI) $30.4 \pm 5.2$ idi. PTMK $(n=172)$ ve PTK $(n=130)$ grupları arasında yaş, VKi ve cinsiyet açısından fark yoktu. Hipertansiyon, diyabet ve tiroid dışı malignite öyküsü olanlarda PTK daha sıkken primer hipotiroidi öyküsü olanlarda PTMK daha sıktı. Tek odaklı tümörü olanlar PTMK grubunda daha fazla iken 3-9 arasında tümör odağı bulunanlar PTK grubunda daha fazlaydı $(p=0.012)$. Ekstratiroidal ekstansiyon oranı PTK olanlarda daha yüksekti $(p<0.001)$. Ayrıca PTK grubunda boyun LN metastazı varlığı daha fazla iken $(p=0.022)$, her iki grupta LN metastazı olanlarda boyun metastazı görülen bölgeler açısından anlamlı fark saptanmadı $(p=0.807)$.

Sonuç: PTMK ve PTK hastaları karşılaştırıldığında tümör boyutu, odak sayısı, ekstratiroidal ekstansiyonu ve boyun LN metastazı varlığı PTK grubunda daha fazla olmasına rağmen her iki grupta LN metastazı görülen bölgeler arasında anlamlı fark saptanmadı. Tüm PTK ve PTMK hastalarında tedavi seçimi ve takibi yapılırken boyun bölgeleri patolojik LN taraması açısından dikkatle incelenmelidir.

Anahtar kelimeler: Papiller tiroid kanseri, mikrokarsinom, lenf nodu

Sorumlu Yazar*: Narin NASIROGLU IMGA, 1Ankara Numune Eğitim ve Araştırma Hastanesi Endokrinoloji ve Metabolizma Hastalıkları Kliniği, 


\section{ABSTRACT}

Aim: Papillary thyroid carcinoma (PTC) is one of the most commonly seen cancers with good prognosis and requires longterm follow-up. Papillary thyroid microcarcinoma (PTMC) is defined as a PTC size $\leq 10 \mathrm{~mm}$ in large diameter. Advanced age, tumor size, number of tumor foci and presence of extrathyroidal extension, pathological lymph node (LN), and distant metastasis affect PTC prognosis negatively. Our aim was to compare clinical, laboratory and tumor characteristics of PTC and PTMC patients

Material and Method: A total of 302 PTC patients who underwent total thyroidectomy between April 2014 and October 2017 in Ankara Numune Education and Research Hospital were evaluated retrospectively. Postoperative tumor size, number of foci, localization and extrathyroidal extension status were recorded.

Results: Patients were $80.8 \%$ female, $19.2 \%$ male. The mean age was $46.48 \pm 12.3$, while the body mass index (BMI) was $30.4 \pm$ 5.2. No difference was found in terms of age, BMl, and gender between the groups of PTMC $(n=172)$ and PTC $(n=130)$. PTC is more frequently seen in patients with hypertension, diabetes, and non-thyroidal malignancy, while PTMC is more frequent in those with primary hypothyroidism. Unifocal tumors were more frequent in the PTMC group, whereas tumor focuses between 3-9 were more frequent in the PTC group $(p=0.012)$. The extrathyroidal extension rate was higher in PTC group ( $p<0.001)$. Neck LN metastasis was more prevalent in the PTC group $(p=0.022)$, but there was no significant difference between the neck LN metastases regions between PTC and PTMC groups $(p=0.807)$.

Conclusion: Despite the presence of large tumor size, multifocality, extrathyroidal extension and neck LN metastasis in PTC group, no difference was found between neck LN metastasis regions between PTMC and PTC patients. Careful examination of all neck regions for pathologic LN scan should be performed in PTC and PTMC patients.

Keywords: Papillary thyroid carcinoma, microcarcinoma, lymph node

\section{Giriş}

Tiroid kanseri en yaygın görülen endokrin malignensilerden biri olup tüm kanserlerin\% $0.5-\% 1.5$ kadarını oluşturur [1]. Papiller tiroid karsinomları (PTK) en sık görülen türü olup tüm tiroid kanserlerinin \% 85' inden fazlasını oluştururlar. Her ne kadar iyi bir prognoza sahip olsa da uzun dönem mortalite oranı \%10 kadar yüksek olabileceğinden ömür boyu takip gerektirir [2,3]. Tiroid cerrahisi sonrası PTK tümör boyutu $\leq 10 \mathrm{~mm}$ ise papiller tiroid mikrokarsinom (PTMK) olarak tanımlanmış olup, hastalığa özgü mortalite oranlarının $<\% 1$, lokorejyonel nüks oranının $\% 2-6$, uzak nüks oranının ise $\%$ 1-2 olduğu bildirilmiştir [4,5]. Tümör boyutu büyüklüğü, odak sayısı, tiroid kapsülü dışına ekstansiyonu ve lateral lenf nodu (LN) metastazı varlığı PTK hastalarında uzun dönem mortalite ve nüks oranlarını belirler [6].

Multifokal PTK' da tümör odakları tek tiroid lobuna yada her iki loba yerleşmiş olabilir. Multifokalitenin, tümör hücrelerinin intraglandüler yayılımı ile birincil odaktan ortaya çıktığı düşünülmektedir [7]. Multifokalite insidansının
\%18-87 arasında değiştiği gözlemlenmiştir [8]. Multifokal hastalık unifokal hastalık ile karşılaştııılığında, multifokalite kötü prognoz ve nüks oranının yüksekliği ile ilişkili bulunmuştur [9]. Hem PTK hem de PTMK olanlarda boyun LN metastazı görülebildiği bilinmektedir. En sık santral LN metastazı görülmesine rağmen lateral LN metastazı oranları küçümsenemeyecek kadar fazladır.

Çalışmamızın amacı total tiroidektomi operasyonu sonrası PTK ve PTMK saptanan hastaların verilerini karşılaştırıp demografik, klinik, laboratuvar ve patoloji özelliklerinin arasındaki farklılıkları belirlemektir.

\section{Gereç ve Yöntem}

Çalışmada Nisan 2015 ve Kasım 2017 tarihleri arasında Ankara Numune Eğitim ve Araştırma Hastanesi MemeEndokrin Cerrahisi kliniğinde tiroid cerrahisi yapılıp Endokrin ve Metabolizma Hastalıkları kliniğinde takip edilen 921 hastanın datası retrospektif olarak incelendi. Bunlardan total tiroidektomi yapılıp PTK ve PTMK saptanan ve çalışma kriterlerine uygunluğu sağlanan 302 hasta çalışmaya dahil 
edildi. Çalışmaya dahil edilme kriterleri; hastaların preoperatif boy ve kilo ölçümünün yapılmış olması, önceden tiroid cerrahisi öyküsü olmaması, ötiroid multinodüler guatr (ÖMNG), Graves hastalığı veya malignite şüphesi nedeniyle opere edilenler, operasyon öncesinde nodüle yönelik sitolojik

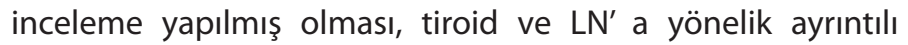
boyun ultrasonografisinin (USG) mevcut olması, operasyon öncesi tiroid fonksiyon testi (TFT) ve tiroid otoantikorlarının mevcut olması, postoperatif tiroid bezinin histopatolojik olarak incelenmiş olmasıdır. Hastaların özgeçmişlerinde Tip 2 Diyabetes Mellitus (DM), hipertansiyon (HT), primer hipotiroidi, koroner arter hastalığı (KAH) ve tiroid dışında başka malignite öyküsü ile ailede tiroid malignitesi öyküsü (1. ve 2. dereceden akrabalarda) hasta dosyalarından incelenip kaydedildi. Postoperatif patoloji raporları incelenen hastalar PTMK ve PTK olarak ikiye ayrıldı. Tiroid bezinde tümör odağı sayısı ve lokalizasyonu, ekstratiroidal ekstansiyon yapıp yapmadığı kaydedildi. Tümör odakları tek odak ve birden fazla odaklı olarak ayırt edildi. Odak sayısı birden fazla olanalar 2 odak, 2-9 odak ve $\geq 10$ odak olarak sınıflandırıldı. Amerikan Kanser Ortak Komitesi (AJCC) yapılan son çalışmalarda 45 yaş sınırını hastaları sınıflanmak için bir kesim değeri olarak benimsediğinden hastalar ayrıca 45 yaş altı ve üstü olarak sınıflandırıldı[6].

Ötiroidizm tanımlaması Tiroid Stimulan Hormon (TSH) (referans aralığı, $0.27-4.2 \mathrm{mlU} / \mathrm{ml}$ ), serbest triiyodotironin (sT3; referans aralığı, 2.0-4.4 pg/ml), ve serbest tiroksin (sT4; referans aralığı, 0.87-1.7 ng/dl) değerlerinin normal referans aralıklarında olması ile yapıldı. Hastaların boy ve kiloları operasyon öncesi ölçülen değerler baz alınarak kaydedildi. Vücut kitle indeksi (VKI) hesaplaması vücut ağırlığının (kg) boyun $(m)$ karesine bölünmesiyle elde edildi.

Boyun USG operasyon öncesi tüm hastalara Endokrinoloji ve Metabolizma Hastalıkları kliniğinde Toshiba Aplio 500 USG cihazı (Toshiba Medical Systems, Tokyo, Japonya) kullanılarak 7.5 MHz linear transducer ile yapıldı. Tiroid bezi hacmi her lob için eliptik şekil hacmi (Uzunluk x Genişlik x Yükseklik x 0.479) kullanılarak hesaplandı [10]. Operasyon sonrası hastalık nüksü düşünülüyorsa USG eşliğinde ince iğne aspirasyon biyopsisi (iiAB) ve tiroglobulin aspirasyon yıkama yöntemi kullanılarak araştırıldı. Ankara Numune Eğitim Araştırma Hastanesi etik kurulundan çalışma için onay alınarak Helsinki Illkeler Deklarasyonuna uyularak gerçekleştirildi.

\section{Laboratuvar ölçümleri}

Serbest T3, serbest T4 ve TSH, tiroglobulin antikor (TGAb) ve TPO antikor (TPOAb) ölçümü immünokemilüminesan analiz yöntemiyle otomatik analizör UniCel Dxl 800 (Beckman Coulter Inc., Brea, CA, ABD) immunoassay cihazı ile ölçüldü. Serum TGAb için normal laboratuvar referans aralığı 0-115 U/ml ve TPOAb için normal laboratuvar referans aralığı 0-34 U/ml idi. Otoantikor değerlerinin laboratuvar referans aralığı üst sınırının üzerinde olması antikor pozitifliği mevcudiyeti olarak kabul edildi.

\section{İstatiksel yöntem}

İstatistiksel analizler Statistical Package for Social Sciences (SPSS) için Windows 20 (SPSS, Inc., Chicago, IL, USA) yazılımı kullanılarak yapıldı. Sayısal değişkenlerin normal dağılıma uygun olup olmadığı Kolmogorov-Smirnov ve Shapiro-Wilk testleri kullanılarak incelendi. Analizler normal dağılan sayısal değişkenler için ortalama \pm standart sapma kullanılarak, normal dağılmayan değişkenler için ortanca değerler kullanılarak verildi. Normal dağılım gösteren parametreler Student T Testi kullanılarak, normal dağılım göstermeyen parametreler Mann-Whitney U testi kullanılarak karşılaştıııldı. Gruplar arasında anlamlılığı araştırmak için Ki-kare veya Fisher exact testleri kullanılarak karşılaştırma yapıldı. P değeri $0.05^{\prime}$ ten düşükse istatistiksel olarak anlamlı kabul edildi.

\section{Bulgular}

Tablo 1 de total tiroidektomi yapılan 302 hastanın demografik, klinik, patolojik ve laboratuvar özelliklerinin verileri görülmektedir. Tüm hastaların ortalama yaşı $46.48 \pm 12.3$ olup 45 yaş altında 128 hasta varken 45 yaş ve üstünde 174 hasta mevcuttu. Hastaların 244' ü (\%80.8) kadın iken 58' i (\%19.2) erkekti. Ortalama VKi $30.4 \pm 5.2$ olarak tespit edildi. Kronik hastalık öyküsü olarak en fazla Tip 2 DM (\%19.5) ikinci sırada HT (\%17.2) saptandı. Ailede PTK öyküsü oranı $\% 5.9$ bulundu. Tiroid bezi hacmi ortalaması tüm hastalarda $35.8 \pm 37.4 \mathrm{ml}$ olarak saptandı. Preoperatif TSH ortalama değeri 1.620 1.3 $\mathrm{mIU} / \mathrm{ml}$ iken TGAb pozitifliği \%6.3 ve TPOAb pozitifliği \%16.6 hastada mevcuttu. Operasyon endikasyonu en sık ÖMNG nedeniyle (\%57.6) idi. Operasyon sonrası patoloji raporlarına göre unifokal tümörü olanlar (\%64.2) multifokal tümörü olanlara (\%35.8) göre daha fazlaydı. Tümör lokalizasyonu en sık sağ lob yerleşimli (\%37.1) olup ekstratiroidal ekstansiyon oranı \%14.2 idi. Boyun LN metastazı görülme oranı \%22.2 olup lateral metastaz en sık sol tarafta (\%32.8) olma eğilimindeydi. 


\begin{tabular}{|c|c|}
\hline Değişken & Değer \\
\hline Yaş, yıl & $46.48 \pm 12.3$ \\
\hline $\begin{array}{l}\text { Yaş Grubu } n, \% \\
<45 \text { yaş } \\
\geq 45 \text { yaş }\end{array}$ & $\begin{array}{l}128(\% 42.4) \\
174(\% 57.6)\end{array}$ \\
\hline $\begin{array}{l}\text { Cinsiyet } \mathrm{n}, \% \\
\text { Erkek } \\
\text { Bayan }\end{array}$ & $\begin{array}{l}58(\% 19.2) \\
244(\% 80.8)\end{array}$ \\
\hline Boy, cm & $163.9 \pm 7.5$ \\
\hline Kilo, kg & $81.5 \pm 13.7$ \\
\hline VKI, kg/m2 & $30.4 \pm 5.2$ \\
\hline $\begin{array}{l}\text { Kronik hastalık öyküsü } n, \% \\
\text { Tip } 2 \text { DM } \\
\text { HT } \\
\text { Primer hipotiroidi } \\
\text { KAH } \\
\text { Malignite öyküsü }\end{array}$ & $\begin{array}{l}59(\% 19.5) \\
52(\% 17.2) \\
34(\% 11.3) \\
17(\% 5.6) \\
11(\% 3.6)\end{array}$ \\
\hline $\begin{array}{l}\text { Ailede papiller tiroid kanseri } \\
\text { öyküsü n, \% }\end{array}$ & $18(\% 5.9)$ \\
\hline Tiroid bezi hacmi, ml & $35.8 \pm 37.4$ \\
\hline Preoperatif TSH, mIU/mI & $1.620 \pm 1.3$ \\
\hline Preoperatif TGAb, \% & $\% 6.3$ \\
\hline Preoperatif TPOAb, \% & $\% 16.6$ \\
\hline Ortalama tümor boyutu, mm & $14.7 \pm 14.4$ \\
\hline $\begin{array}{l}\text { Preoperatif tanı n, \% } \\
\text { ÖMNG } \\
\text { Graves } \\
\text { Malignite şüphesi }\end{array}$ & $\begin{array}{l}\% 57.6 \\
\% 8.3 \\
\% 16.2\end{array}$ \\
\hline $\begin{array}{l}\text { Tümör odak sayısı n, \% } \\
\text { Tek odak } \\
2 \text { odak } \\
\text { 3-9 odak } \\
\geq 10 \text { odak }\end{array}$ & $\begin{array}{l}194(\% 64.2) \\
52(\% 17.3) \\
53(\% 17.5) \\
3(\% 1)\end{array}$ \\
\hline $\begin{array}{l}\text { Tümör lokalizasyon } \mathrm{n}, \% \\
\text { Sağ } \\
\text { Sol } \\
\text { İstmus } \\
\text { Bilateral }\end{array}$ & $\begin{array}{l}112(\% 37.1) \\
86(\% 28.5) \\
11(\% 3.6) \\
93(\% 30.8)\end{array}$ \\
\hline Ekstratiroidal ekstansiyon & $43(\% 14.2)$ \\
\hline $\begin{array}{l}\text { LN metastazı n, \% } \\
\text { Yok } \\
\text { Var }\end{array}$ & $\begin{array}{l}235(\% 77.8) \\
67(\% 22.2)\end{array}$ \\
\hline $\begin{array}{l}\text { LN metastazı n, } \% \\
\text { Sadece santral } \\
\text { Santral+Sağ } \\
\text { Santral+Sol } \\
\text { Santral+Bilateral }\end{array}$ & $\begin{array}{l}17(\% 25.4) \\
20(\% 29.9) \\
22(\% 32.8) \\
8(\% 11.9)\end{array}$ \\
\hline \multicolumn{2}{|c|}{$\begin{array}{l}\text { VKI: Vücut kitle indeksi DM: Diyabetes Mellitus HT: Hipertansiyor } \\
\text { KAH: Koroner arter hastalığı PTK: Papiller tiroid kanseri ÖMNG: } \\
\text { Ötroid multinoduler guatr LN: Lenf nodu }\end{array}$} \\
\hline
\end{tabular}

Mikrokarsinomlar $(\leq 10 \mathrm{~mm})$ daha sessiz olarak nitelendirildiğinden hastalar PTMK ve PTK olarak iki gruba ayrıldı (Tablo 2). Her iki grup karşılaştıııldığında yaş, cinsiyet, boy kilo, VKi açısından anlamlı fark yoktu ( $p>0.05$ ). Her iki grupta 45 yaş altı ve üstü hasta sayısı arasında belirgin fark saptanmadı ( $p=0.495$ ) (Şekil 1). Hipertansiyon, Tip 2 DM ve malignite öyküsü olanlarda PTK daha çok görülürken primer hipotiroidi ve KAH öyküsü olanlarda PTMK daha sıktı $(p<0.001)$. Ailede PTK öyküsü arasında gruplar arasında fark saptanmadı $(p=0.944)$. Tiroid bezi ortalama hacmi her iki grupta benzerdi (33.8 $\pm 32.3 \mathrm{ml}^{\prime}$ e karşın $\left.38.4 \pm 43.4 \mathrm{ml} ; \mathrm{p}=0.305\right)$. Preoperatif laboratuvar özellikleri karşılaştıııldığında TSH $(1.56 \pm 1.30$ ' a karşın 1.66 $\pm 1.48 ; p=0.536$ ) ve TGAb pozitifliği (\%31.7' e karşın $\% 27.3 ; p=0.715$ ) açısından gruplar arasında fark yokken TPOAb pozitifliği olan olgularda PTMK sıklığı daha fazlaydı (\%45.3' e karşın \%27.7; $\mathrm{p}=0.030$ ). PTMK olan olgularda ortalama tümör boyutu $6.3 \pm 5.1 \mathrm{~mm}$ iken PTK olanlarda $25.8 \pm 15.2$ $\mathrm{mm}$ olarak saptandı $(\mathrm{p}<0.001)$. Hastaların preoperatif tanısı incelendiğinde ÖMNG oranı PTMK olan hastalarda daha yüksekken Graves hastalığı ve preoperatif malignite şüphesi nedeniyle ameliyat olanlarda PTK görülme oranı daha yüksekti $(p=0.010)$. Tümör odak sayısı incelendiğinde unifokal tümör oranı PTMK olan olgularda daha fazla saptandı (\%70.3'e karşın \%56.2). Multiodak tümörü olanlar 2, 3-9 ve $>10$ olarak sınıflandırıldığında, 2 odağa sahip olanlarda gruplar arsında anlamlı fark yokken 3-9 odağa sahip olanlar ve $>10$ odağı olan hastalar PTK grubunda daha fazlaydı ( $\mathrm{P}=0.012$ ) (Şekil 2). Tümör lokalizasyonları incelendiğinde; sağ lob ve istmusta tümörü saptananlar PTMK grubunda daha fazla iken sol lobda ve bilateral loblarda tümörü olanlar PTK grubunda daha fazlaydı ancak anlamlı değildi ( $\mathrm{p}=0.06$ ). Tümörün ekstratiroidal ekstansiyon oranı PTK olan hasta grubunda daha fazla saptandı ve istatistiksel olarak anlamlıydı $(p<0.001)$

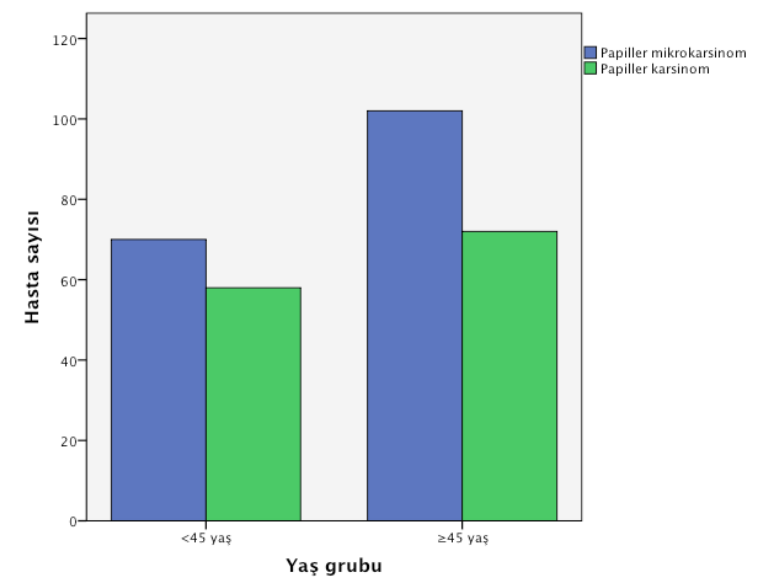

Şekil 1: PTMK ve PTK hastalarında hasta yaşı 45 yaş altı ve üstü olanların dağılım oranı 


\begin{tabular}{|c|c|c|c|}
\hline & PTMK $(n=172)$ & PTK $(n=130)$ & $\mathbf{p}$ \\
\hline Yaş, yıl & $47.1 \pm 11.7$ & $45.2 \pm 13.1$ & 0.294 \\
\hline $\begin{array}{l}\text { Yaş Grubu } n, \% \\
\text { <45 yaş } \\
\geq 45 \text { yaş }\end{array}$ & $\begin{array}{l}70(\% 54.7) \\
102(\% 58.6)\end{array}$ & $\begin{array}{l}58(\% 45.3) \\
72(\% 41.4)\end{array}$ & 0.495 \\
\hline $\begin{array}{c}\text { Cinsiyet } \mathbf{n}, \% \\
\text { Erkek } \\
\text { Bayan }\end{array}$ & $\begin{array}{l}29(\% 50) \\
143(\% 58.6\end{array}$ & $\begin{array}{l}29(\% 50) \\
101(\% 41.4)\end{array}$ & 0.234 \\
\hline Boy, cm & $163.5 \pm 6.9$ & $164.3 \pm 6.9$ & 0.374 \\
\hline Kilo, kg & $71.1 \pm 13.6$ & $82.0 \pm 13.8$ & 0.602 \\
\hline VKI, kg/m2 & $30.4 \pm 5.3$ & $30.4 \pm 5.2$ & 0.980 \\
\hline $\begin{array}{l}\text { Kronik hastalık öyküsü } n, \% \\
\text { Tip } 2 \text { DM } \\
\text { HT } \\
\text { Primer hipotiroidi } \\
\text { KAH } \\
\text { Malignite öyküsü }\end{array}$ & $\begin{array}{l}22(\% 12.8) \\
23(\% 13.4) \\
24(\% 14.0) \\
11(\% 6.4) \\
4(\% 2.3)\end{array}$ & $\begin{array}{l}37(\% 28.5) \\
29(\% 22.3) \\
10(\% 7.7) \\
6(\% 4.6) \\
7(\% 5.4)\end{array}$ & $<0.001$ \\
\hline Ailede papiller tiroid kanseri öyküsü n, \% & $8(\% 44.4)$ & 10(\%55.6) & 0.944 \\
\hline Tiroid bezi hacmi, ml & $33.8 \pm 32.3$ & $38.4 \pm 43.4$ & 0.305 \\
\hline Preoperatif TSH, mIU/ml & $1.56 \pm 1.30$ & $1.66 \pm 1.48$ & 0.536 \\
\hline Preoperatif TGAb, \% & $\% 31.7$ & $\% 27.3$ & 0.715 \\
\hline Preoperatif TPOAb, \% & $\% 45.3$ & $\% 27.7$ & 0.030 \\
\hline Ortalama tümor boyutu, mm & $6.3 \pm 5.1$ & $25.8 \pm 15.2$ & $<0.001$ \\
\hline $\begin{array}{l}\text { Preoperatif tanı n, \% } \\
\text { ÖMNG } \\
\text { Graves } \\
\text { Malignite şüphesi }\end{array}$ & $\begin{array}{l}112(\% 77.2) \\
13(\% 9.0) \\
20(\% 13.8)\end{array}$ & $\begin{array}{l}62(\% 60.2) \\
12(\% 11.7) \\
29(\% 28.2)\end{array}$ & 0.010 \\
\hline $\begin{array}{l}\text { Tümör odak sayısı } n, \% \\
\text { Tek odak } \\
2 \text { odak } \\
\text { 3-9 odak } \\
\geq 10 \text { odak }\end{array}$ & $\begin{array}{l}121(\% 70.3) \\
30(\% 17.4) \\
20(\% 11.6) \\
1(\% 0.6)\end{array}$ & $\begin{array}{l}73(\% 56.2) \\
22(\% 16.9) \\
33(\% 25.4) \\
2(\% 1.5)\end{array}$ & 0.012 \\
\hline $\begin{array}{l}\text { Tümör lokalizasyon } \mathbf{n}, \% \\
\text { Sağ } \\
\text { Sol } \\
\text { İstmus } \\
\text { Bilateral }\end{array}$ & $\begin{array}{l}73(\% 42.4) \\
46(\% 26.7) \\
8(\% 4.7) \\
45(\% 26.2)\end{array}$ & $\begin{array}{l}39(\% 30.0) \\
40(\% 30.8) \\
3(\% 2.3) \\
48(\% 36.9)\end{array}$ & 0.06 \\
\hline $\begin{array}{l}\text { Ekstratiroidal ekstansiyon n, \% } \\
\text { Yok } \\
\text { Var }\end{array}$ & $\begin{array}{l}161(\% 93.6) \\
11(\% 6.4)\end{array}$ & $\begin{array}{l}98(\% 75.4) \\
32(\% 24.6)\end{array}$ & $<0.001$ \\
\hline $\begin{array}{l}\text { LN metastazı n, \% } \\
\text { Yok } \\
\text { Var }\end{array}$ & $\begin{array}{l}142(\% 60.4) \\
30(\% 44.8)\end{array}$ & $\begin{array}{l}93(\% 39.6) \\
37(\% 55.2)\end{array}$ & 0.022 \\
\hline $\begin{array}{l}\text { LN metastazı n, \% } \\
\text { Sadece santral } \\
\text { Santral+Sağ } \\
\text { Santral+Sol } \\
\text { Santral+Bilateral }\end{array}$ & $\begin{array}{l}8(\% 26.7) \\
10(\% 33.3) \\
8(\% 26.7) \\
4(\% 6.0)\end{array}$ & $\begin{array}{l}9(\% 24.3) \\
10(\% 27.0) \\
14(\% 37.8) \\
4(\% 6.0)\end{array}$ & 0.807 \\
\hline
\end{tabular}




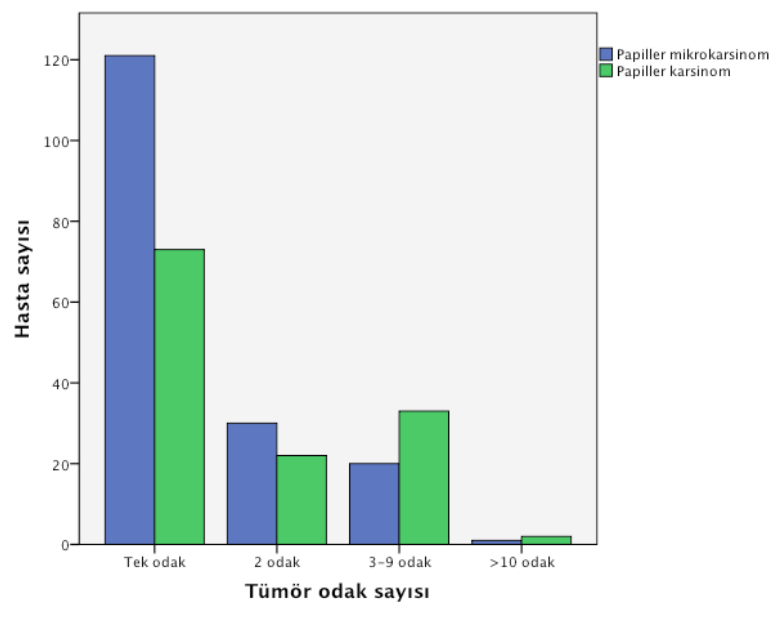

Şekil 2: PTMK ve PTK hastalarında tümör odak sayısı ile hasta sayısı dağılım oranı

Boyun LN metastazı olan hastaların \%44.8' inde PTMK varlığı mevcutken \%55.2' sinde PTK mevcut olup istatistiksel olarak anlamlı fark bulundu ( $p=0.022)$. Boyun bölgelerine göre incelendiğinde sağ LN metastazı oranı PTMK grubunda fazla iken sol LN metastazı olan olgular PTK olan grupta daha fazla saptandı ancak istatiksel olarak anlamlı değildi ( $p=0.807)$.

\section{Tartışma}

Tiroid kanseri, son yıllarda dünya çapında insidansı hızla artan ve sık görülen bir endokrin malignitedir [11]. Çalışmamızda PTK tanısı alan hastalar demografik, laboratuvar ve tümör boyutu ve patolojik özellikleri yönünden incelendi. Hastalarımızın demografik verileri incelendiğinde bayan cinsiyetin çoğunlukta olduğu (\%80.2) ve erkeklere oranla 4 kat daha fazla olduğu gözlemlendi. Jung ve ark. kadınlarda en sık görülen kanser türünü tiroid kanseri olarak tespit etmiş olup bunu sırasıyla görülme sıklığına göre meme, kolon, mide ve akciğer kanserleri takip etmiştir [12]. Bir çalışmada 1975-2009 yılları arasında hastaneye başvuran takipli hastaların verilerinin incelenmesi sonucunda PTK insidansının bu süreçte yaklaşık üç katına çıktığı görülmüştür. Ayrıca kadınlarda tiroid kanserindeki mutlak artış erkeklere göre yaklaşık 4 kat daha fazla bulunmuş olup bu bulgular verilerimizi destekler niteliktedir [13]. Çalışmamızda PTMK grubunda ortalama yaş 47, PTK grubunda ise 45 olarak saptandı. Türkiye' de ortalama menopoz yaşı 47 olarak tespit edilmiştir [14]. Bu göz önünde bulundurularak bayan hastalarımızda ortalama tiroid kanseri görülme yaşının menopoza giriş dönemine denk geldiği ifade edilebilir. Östrojenin tiroid kanseri üzerindeki etkisini inceleyen literatür tutarsızdır ve kısmen epidemiyolojik çalışmalara veya anekdot raporlarına dayanmaktadır ayrıca menopoz sonrası tiroid kanseri davranışına ilişkin veriler de çelişkilidir. Tiroid kanseri insidansının menopozdan sonra azaldığı belirtildiği gibi [15], menopoz sonrası PTK nüks oranında artış olabileceği de öne sürülmüştür [16]. Bu konuda daha uzun dönemli ve geniş hasta popülasyonuyla yapılmış çalışmalara ihtiyaç vardır. Ancak menopoza giriş döneminde hastalarda aile öyküsü ve takipsiz tiroid nodülleri gibi risk faktörleri varsa hastaların tiroid kanseri açısından daha dikkatli değerlendirilmesi gerekmektedir.

Tiroid hastalığı dışındaki hastalık öyküsü açısından incelendiğinde çalışmamızda PTK olan hastalarda en sık Tip 2 DM saptanırken PTMK olan hastalarda en sık primer hipotiroidi görüldü. Ayrıca her iki grupta ortalama VKi 30.4 kg/ m2 olarak tespit edilmiş olup hastalarımız obezite sınırında tespit edildi. Diyabetli olan ve olmayanların karşılaştırıldığı bir çalışmada DM olan erkek ve kadın hastalarda tiroid kanseri riskinin 1.34 kat arttığı, duyarlılık testi yapıldıktan sonra da sadece kadınlarda 1.38 kat kadar arttığı ile ilişkilendirilmiştir [17]. Obez hastalar daha ileri evre ve daha agresif PTK formlarıyla karşımıza çıktıklarından obez hastaların tiroid kanseri için taranması gerektiği düşünülmektedir[18]. TURDEP 2 çalışmasında da Türkiye' de Tip 2 DM görülme oranı \%13.7 olarak tespit edilmiş olup [19] diyabetli ve metabolik sendromlu hastalarda tiroid kanseri yönünden dikkatli olunması gerektiğini düşünmekteyiz. Çalışmamızda PTMK olanlarda TPOAb sıklığı PTK olan hastalara göre daha sık görüldü. Hashimoto tiroiditi artmış papiller tiroid kanseri insidansı ile ilişkili bulunmuştur [20]. Özgeçmişinde primer hipotiroidi öyküsü olan hastalarımız PTMK grubunda daha fazla bulunduğundan TPOAb pozitifliğinin bu grupta daha fazla görülmesi bununla ilişkili olabilir.

Tiroid kanserli olgularda multifokalite ve ekstratiroidal ekstansiyon ile hastalık prognozu arasında doğrusal bir ilişki mevcuttur. Yapısal hastalık nüks riski tek odaklı PTMK olanlarda \% 1-2 oranında, multifokal PTMK olanlarda \% 4-6 kadar değişen oranlarda görülebilir [4]. Multifokal PTK ve santral LN pozitifliği arasında anlamlı bir ilişki olduğu gibi tümörün multifokal olması LN metastazı olma eğilimini arttırır ve tümör agresifliğinin bir işareti olarak kabul edilmektedir [21]. Ekstratiroidal ekstansiyonun PTK risk sınıflamasında önemli yeri vardır. ATA kılavuzunda ekstratiroidal ekstansiyonu olmayan tümörler düşük risk sınıfında yer alırken olanlar ise orta ve yüksek risk sınıfına dahil edilmişlerdir [6]. 
Çalışmamızda da PTK olgularında tümör odak sayısı, ekstratiroidal ekstansiyon ve boyun LN metastazı PTMK olanlara oranla daha fazla bulunmuş olup literatür ile uyumludur. Düşük riskli PTK hastalarında LN metastazlarının klinik olarakönemi olmadığı düşünülse de yapılan Surveillance, Epidemiology, and End Results (SEER) çalışmasında 9904 PTK hastasında, LN metastazı, 45 yaş üzeri olma, uzak metastaz varlığı ve büyük tümör boyutu çok değişkenli analizde sağ kalımı anlamlı düzeyde azalttığını öngörmüştür [22]. Ito ve ark. tarafından yapılan retrospektif çalışmada PTK hastaları ortalama 75 ay (aralık; 1-246 ay) izlenmiş,; mikrokarsinomu olan 1235 hastada 5 yılda \%1.7 ve 10 yılda \%3.8 oranında LN metastazı gösterildiği kanıtlanmıştır [23]. Çalışmamızda PTK olan hastalarda LN metastazı sıklığı daha fazla saptandı ancak PTMK olan hastaların uzun dönemli takipte LN metastazı yönünden takip sonuçları bilinmemektedir. Her iki grupta boyun LN metastazı bölgeleri açısından anlamlı fark bulunmadı. Bu nedenle hem PTMK hem de PTK hastalarında LN metastazı açısından boyun bölgelerine yönelik uygun taramanın yapılması gerektiğini düşünmekteyiz.

Çalışmamızın limitasyonları; hastalar retrospektif olarak incelendiğinden eşlik eden diğer hastalıkların verisi net olmadığından sadece en sık görülen hastalıklar ile ilgili istatistik hakkında yorum yapıldı. Ayrıca hastalarımızın uzun dönem takibi olmadığından survey ve hastalık prognozu ile ilgili yorum yapılamamıştır.

Sonuç olarak PTMK ve PTK hastalarında tümör boyutu, odak sayısı, tümörün ekstratiroidal ekstansiyonu ve LN metastazı varlığı PTK grubunda daha fazla saptanmasına rağmen boyunda LN metastazı görülen bölgeler açısından her iki grup arasında anlamlı fark saptanmadı. Hem PTMK hem de PTK hastalarında operasyon öncesi ve sonrası tedavi seçimi ve hastalık takibi yapılırken boyun bölgelerinin dikkatli bir şekilde taranması önemlidir.

\section{Maddi Destek ve Çıkar îlişkisi}

Çalışmayı maddi olarak destekleyen kişi/kuruluş yoktur ve yazarların çıkara dayalı bir ilişkisi yoktur.

\section{Kaynaklar}

1. Schlumberger MJ. Papillary and follicular thyroid carcinoma. N Engl J Med 1998; 338: 297-306.

2. Sherman SI. Thyroid carcinoma. Lancet 2003; 361: 501-11.

3. Kuo SF, Lin SF, Chao TC, Hsueh C, Lin KJ, Lin JD. Prognosis of multifocal papillary thyroid carcinoma. Int J Endocrinol 2013;2013
4. Mazzaferri EL. Management of low-risk differentiated thyroid cancer. Endocr Pract 2007; 13: 498-512.

5. Hay ID. Management of patients with low-risk papillary thyroid carcinoma. Endocr Pract 2007; 13: 521-33

6. Haugen BR, Alexander EK, Bible KC et al. American Thyroid Association management guidelines for adult patients with thyroid nodules and differentiated thyroid cancer: the American Thyroid Association guidelines task force on thyroid nodules and differentiated thyroid cancer. Thyroid 2016; 26: 1-33.

7. Katoh R, Sasaki J, Kurihara H, Suzuki K, lida Y, Kawaoi A. Multiple thyroid involvement (intraglandular metastasis) in papillary thyroid carcinoma. A clinicopathologic study of 105 consecutive patients. Cancer 1992; 70: 1585-90.

8. So YK, Kim MW, Son YI. Multifocality and bilaterality of papillary thyroid microcarcinoma. Clin Exp Otorhinolaryngol 2015; 8: 174.

9. Qu N, Zhang L, Ji Q-H et al. Number of tumor foci predicts prognosis in papillary thyroid cancer. BMC Cancer 2014; 14: 914.

10. Brunn J, Block U, Ruf G, Bos I, Kunze WP, Scriba PC. Volumetric analysis of thyroid lobes by real-time ultrasound (author's transl). Dtsch Med Wochenschr. 1981; 106: 1338-40.

11. Jemal A, Bray F, Center MM, Ferlay J, Ward E, Forman D. Global cancer statistics. CA Cancer J Clin 2011; 61: 69-90.

12. Jung KW, Won YJ, Kong $\mathrm{HJ}$ et al. Cancer statistics in Korea: incidence, mortality, survival, and prevalence in 2012. Cancer research and treatment: official journal of Korean Cancer Association. 2015; 47: 127.

13. Davies L, Welch HG. Current thyroid cancer trends in the United States. JAMA Otolaryngol Head Neck Surg. 2014; 140: 317-22.

14. Ceylan B, Özerdoğan N. Factors affecting age of onset of menopause and determination of quality of life in menopause. Turk J Obstet Gynecol 2015; 12: 43.

15. Sakoda LC, Horn-Ross PL. Reproductive and menstrual history and papillary thyroid cancer risk: the San Francisco Bay Area thyroid cancer study. Cancer Epidemiol Biomarkers Prev 2002; 11: 51-7.

16. Candanedo-Gonzalez FA, Gamboa-Dominguez A. Postmenopause is associated with recurrence of differentiated papillary thyroid carcinoma. Med Hypotheses 2007; 69: 209-13.

17. Yeo $\mathrm{Y}, \mathrm{MaSH}, \mathrm{Hwang} \mathrm{Y}$ et al. Diabetes mellitus and risk of thyroid cancer: a meta-analysis. PloS one. 2014; 9: e98135.

18. Harari A, Endo B, Nishimoto S, Ituarte PH, Yeh MW. Risk of advanced papillary thyroid cancer in obese patients. Arch Surg 2012; 147: 805-11. 
19. Satman I, Omer B, Tutuncu $Y$ et al. Twelve-year trends in the prevalence and risk factors of diabetes and prediabetes in Turkish adults. Eur J Epidemiol 2013; 28: 169-80.

20. Kim KW, Park YJ, Kim EH et al. Elevated risk of papillary thyroid cancer in Korean patients with Hashimoto's thyroiditis. Head \& neck 2011; 33: 691-95.

21. Al Afif A, Williams BA, Rigby MH et al. Multifocal papillary thyroid cancer increases the risk of central lymph node metastasis. Thyroid 2015; 25: 1008-12.
22. Podnos YD, Smith D, Wagman LD, Ellenhorn JD. The implication of lymph node metastasis on survival in patients with welldifferentiated thyroid cancer. Am Surg 2005; 71: 731-4

23. Ito $Y$, Miyauchi A, Kihara M, Higashiyama T, Kobayashi K, Miya A. Patient age is significantly related to the progression of papillary microcarcinoma of the thyroid under observation. Thyroid 2014; 24: $27-34$ 